\title{
Compared of Surface Roughness Nitride Layers formed on Carbon and Low Alloy steel
}

\author{
Wayan Sujana ${ }^{1}$, Komang Astana Widi ${ }^{2}$ \\ Mechanical Engineering Department, National Institute of Technology of Malang, Karanglo Street Km 2, Malang East Java- \\ Indonesia
}

\begin{abstract}
A comprehensive study of fluidized bed nitriding was performance on a carbon steel (grade AISI St 41) and low alloy steel (grade AISI 4140) at $550{ }^{\circ} \mathrm{C}$ in $20 \% \mathrm{~N}^{2}$ and $80 \% \mathrm{NH}^{3}$ atmosphere at a flow rate gasses of $0.7 \mathrm{~m}^{3} / \mathrm{hr}$. Various surface roughness were used to incorporate nitrogen into these steels. The nitride layer formed at AISI 4140 showed better surface roughness and surface hardness than AISI St 41. With low chromium alloy (grade AISI 4140), nitrogen diffusion is more uniform in the lower surface roughness after nitriding process. It has been found that the surface microhardness of the compound layer increases with decreasing surface roughness and chromium alloy contents. The layer nitride has a decrease surface roughness ranging from $50 \%$ at 0,1 $\mu \mathrm{m}$ to about $17 \%$ at 0,5 $\mu \mathrm{m}$. On the contrary, the carbon steel without chromium alloy (grade AISI St 41) sample show an enhance surface roughness between 1.3 to 2.5 times after nitriding process, but on 0.5 m surface roughness sample show a decrease surface roughness of about 10\%. All sample show an enhanced surface microhardness after nitriding significantly. Chromium alloy is found to enhanced the nitriding efficiency. Without chromium in the steel, a lower surface roughness provides a supplementary amount of implanted nitrogen available for further diffusion, and the uniform of the surface passive oxide. So, with limited surface roughness, more uniform layers with higher amounts of nitrogen can be achieved by low chromium alloy. However, with limited solubility of nitrogen atom in $\alpha$-Fe into iron nitride form, the nitrogen becomes supersaturated reaction and nitride layer is more brittle and porosity. It is can be ascribed to the nitrogen solubility in the nitride layer, which at AISI St 41 is higher due to the formation of porosity phase while at AISI 4140 a phase rich in nitrogen (Yand \& phases) is formed.
\end{abstract}

Keywords-roughness, fluidized bed, nitride layers, microstructures, SEM.

\section{INTRODUCTION}

Fluidized bed reactor is more effective dan efficient than conventional reactor [1]. Surface roughness plays an important role in improving the quality of a component at the time of its use, especially in the application of cutting tool and sometimes coated parts, electric hardware, automotive component [1,2]. Increase the surface hardness, alter the surface chemistry and to increase the surface roughness are important things to observe the surface modification in nitriding component. Specific characteristics defined surface roughness mentioned above has a close relationship with nature and durability surface roughness. Thereby to increase the life time of cutting tool components generally utilize surface hardening treatment especially thermochemical treatment the right to apply is nitriding because this treatment has the advantage of precision for most components is better than other thermochemical treatments such as carburising, carbonitriding etc. Investigated of surface roughness effects is already discussed [3,4,5].

However, in the nitriding thermochemical treatment which although in the process will include a nitrogen atom (alter the composition of the material) but will not affect the dimensions of the components, so in this study will focus on changes in surface roughness after gas nitriding treatment by utilizing materials with a chemical composition different. And to better focus the composition of concern in this study is the composition of the chromium contained in the specimens.

\section{Experimental Procedure}

The material used in this study is a type of carbon steel (AISI St 41) which does not have the elements chromium and type of tool steel (AISI 4140) which has the element chromium. Sectioning, grinding and polishing were used for preparation on the surface specimen for identification of surface roughness. Both specimens will be treated the same nitriiding gas namely the fluidised bed reactors at temperatures of $550^{\circ} \mathrm{C}$ with the composition of the gas mixture of $20 \% \mathrm{~N}_{2}$ and $80 \% \mathrm{NH}_{3}$ gas at a flow rate of $0.7 \mathrm{~m} 3 / \mathrm{hr}$ and a process for 4 hours is further cooled by air cooling. Then, will be given the test specimen 
surface roughness before and after nitriding treatment. The surface roughness value changes that occur will be correlated with the morphological observation and characteristics of hard nitride layer is formed utilizing microstructure and SEM examination.

\section{RESULTS AND DISCUSSION}

Table 1 shows the composition ratio of the second test specimen before nitriding treatment. It appears that the AISI St 41 does not contain chromium while the AISI 4140 has a chromium content of up to $1.07 \%$. Chemical composition content in material especially chrome, which very important influenced the homogeneity of nitride compound layers [8]. In this investigation we will learn more about it, in which the specimens used with and without chrome alloys.

TABLE 1

\section{COMPOSITION OF AISI 4140 AND AISI St 41}

\begin{tabular}{|c|c|c|c|c|c|}
\hline Specimen & \multicolumn{5}{|c|}{ Conc. (\%) } \\
\hline & $\mathbf{C}$ & $\mathbf{S i}$ & Mn & Cr & Mo \\
\hline AISI 4140 & 0.41 & 0.34 & 0.81 & 1.07 & 0.19 \\
\hline AISI St 41 & 0,12 & 0,25 & 0,6 & - & - \\
\hline
\end{tabular}

The surface hardness of AISI 4140 of approximately $872 \mathrm{HV}$ after fluidized bed nitriding, it is show that nitride compound layer is formed on the top of surface [8]. This is supported also from the results of testing of the type AISI steel St 41 which has a varied surface roughness on the condition before and after the nitriding process compared to specimens tool steel AISI 4140 ( Figure 1 ). This can be explained that the phase of forming compound layers, when there is nitrogen activity (an) that have lower, so nitrogen solution to the phase is thoroughly, so that phase $\gamma^{\prime} \mathrm{Fe} 4 \mathrm{~N}$ is formed. With nitrogen and carbon content that increase together with higher alloy nitride form composition, it causes balance of forming phase $\gamma^{\prime} \mathrm{Fe} 4 \mathrm{~N}$ is passed, and it causes phase of $\varepsilon f e 2-3 \mathrm{~N}$ is formed. So, phase $\gamma^{\prime}$ generally will be located beneath phase of $\varepsilon \mathrm{Fe} 2 \mathrm{~N}$ [9].

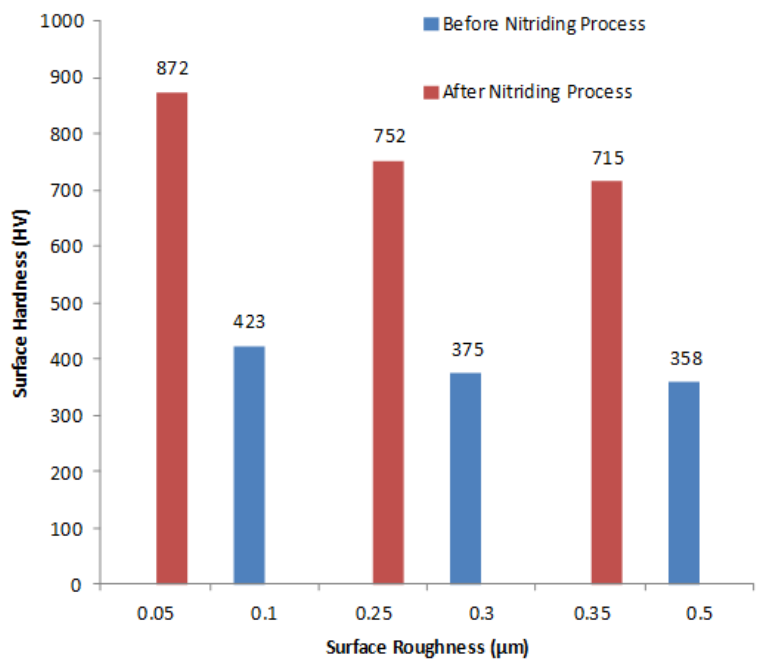

(A)

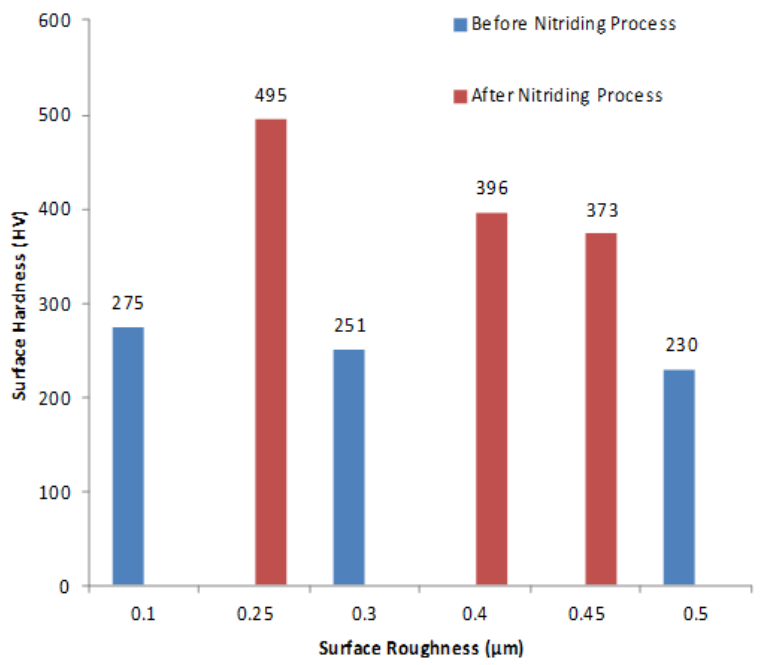

(B)

FIGURE 1. COMPARED OF SURFACE ROUGHNESS AND SURFACE HARDNESS ON A) AISI 4140 AND B) AISI ST 41 BEFORE AND AFTER NITRIDING PROCESS

The surface hardness of the different surface zones of a nitrided specimen. The compound layer usually contains pores and britle characteristic have a relatively low surface hardness and poor mechanical properties. If nitrogen atomic content is increased so it passes saturated limit of phase $\varepsilon$ formed, so activity of diffused $\mathrm{N}$ atoms will supersaturated reactions to form $\mathrm{N}_{2}$ gas. We can says that the denitriting reaction. This reaction product is called porosity, which is showed in figure 2 , is effected by saturation with nitrogen element. 


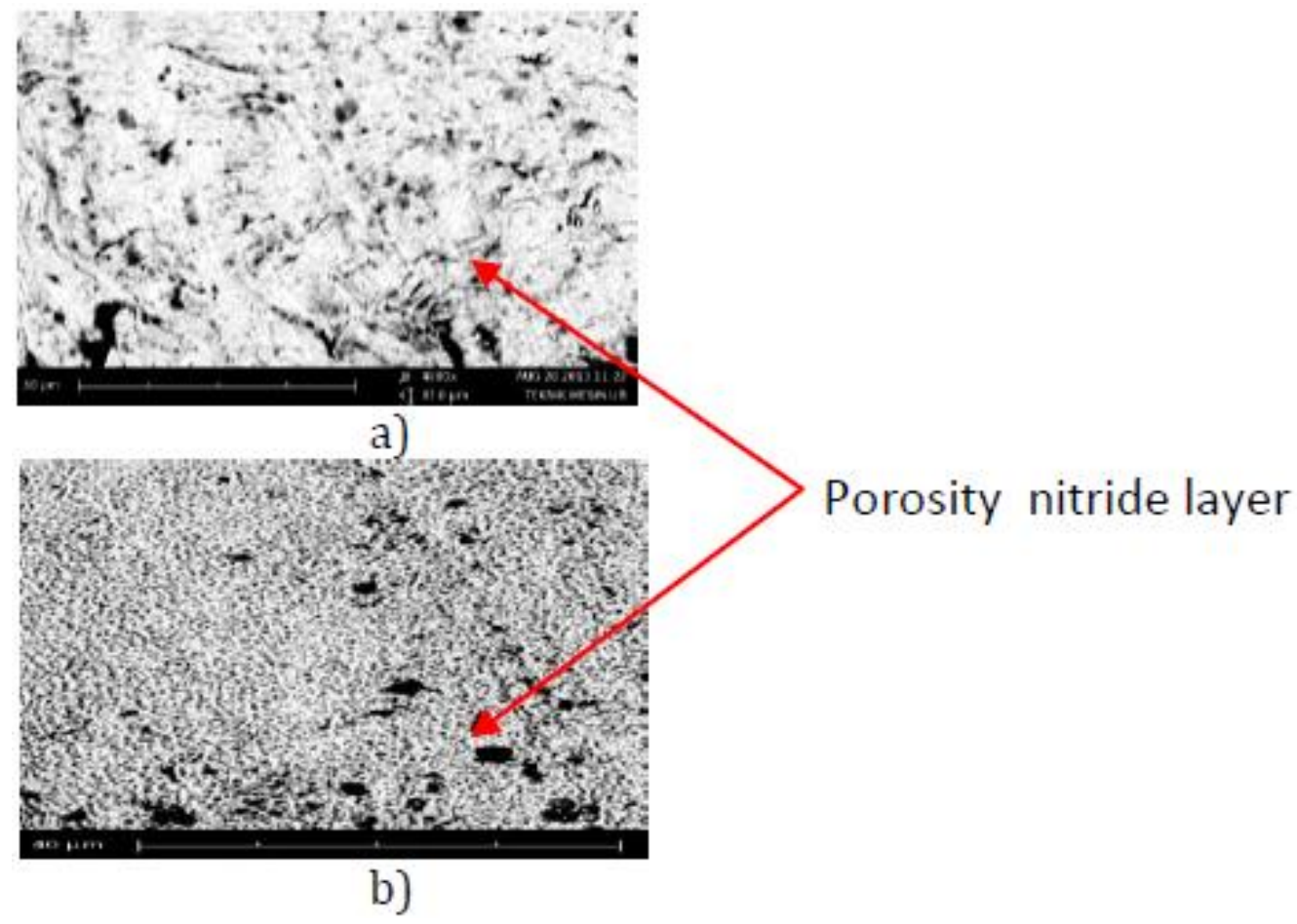

Figure 2. SURFACE TOPOGRAPHY A) AISI 4140, B) AISI St 41

Observations on the second specimen after nitriding shows different surface topography where steel AISI St 41 has a surface more uniform micro porosity / homogeneous compared with the type of steel AISI 4140 ( Figure 2 ). This shows the nitride layer is formed not too loud and very easily detached from the substrate interface as shown in figure 3 . The data had a good correlation with the surface hardness and the surface roughness nitride layer, respectively. Brittle surface nitride compound layer depend on nitriding treatment technology [7]. It is shown in this observation in which the compound nitride layer large amount of spalling.

Brittle nitride compound layer formed in this treatment can be mechanically removed conventionally by grinding. It is shows that fluidized bed nitriding treatment can produces only diffusion layer without formation of the compound layer.

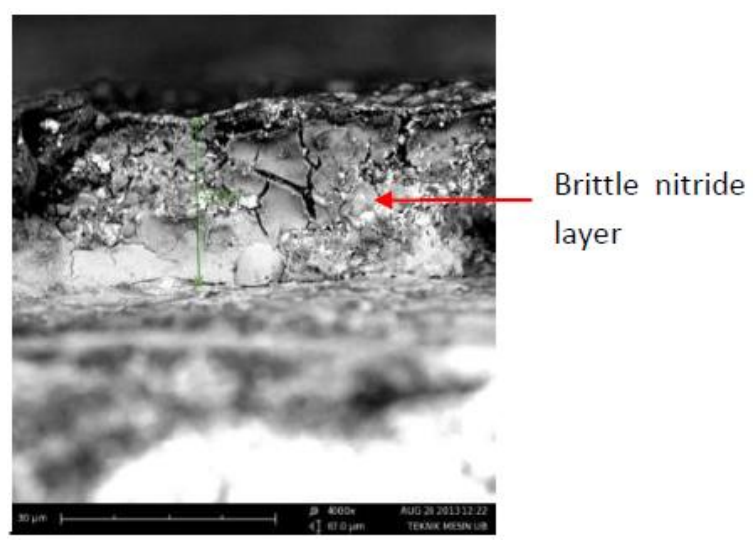

(A)

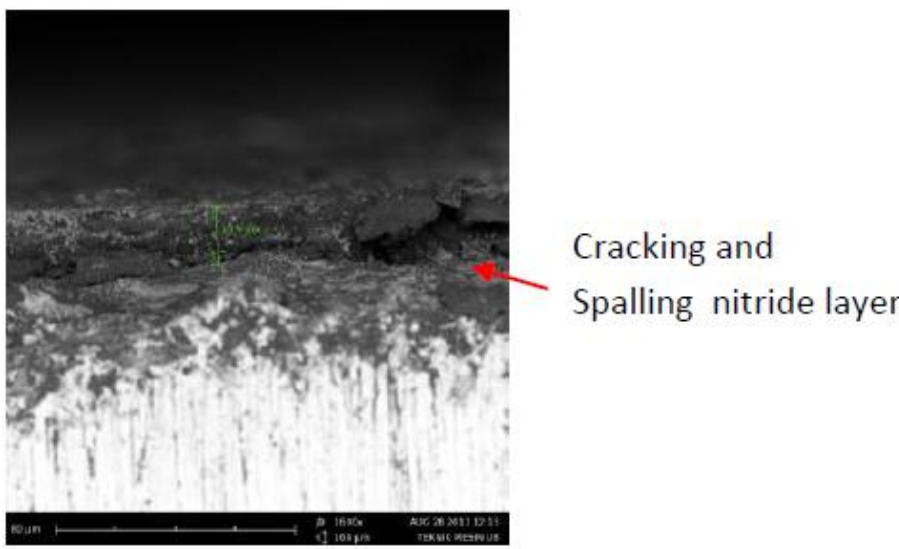

(B)

FIGURE 3. NITRIDE LAYER OF AISI St 41 A) BRITLENESS B) SPALLING

Surface hardness will increase with decreasing surface roughness values. An increase in surface roughness as a result of the formation porosity which is nitrogen atom solubility is very high on the surface. It is also supported by solubility limitations of the alloying element especially chrome element. 


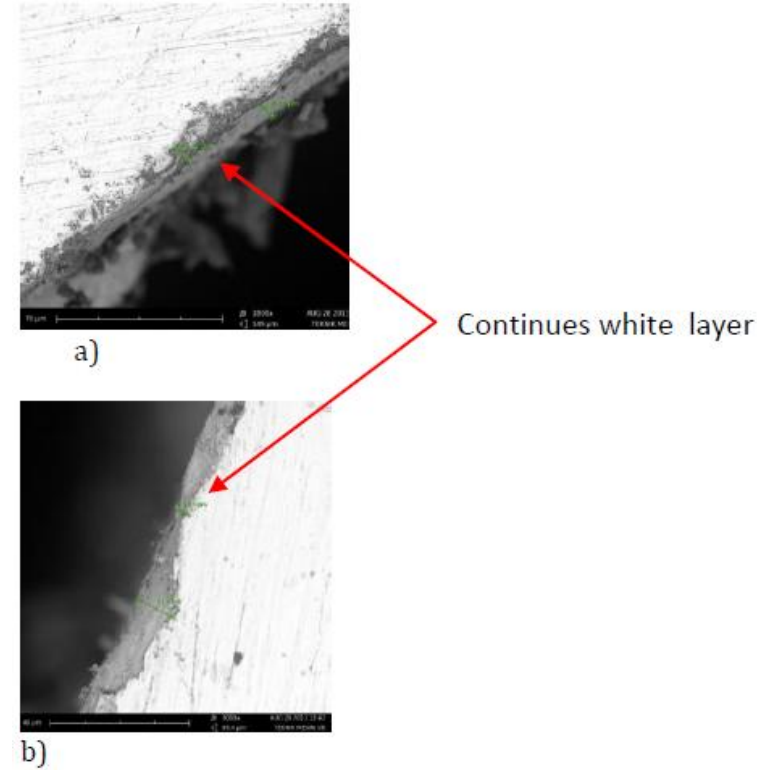

FigURE 4. SURFACE MORPHOLOGY OF AISI 4140 WITH SURFACE ROUGHNESS a) $0,1 \mu \mathrm{m}$ AND b) $0,5 \mu \mathrm{m}$

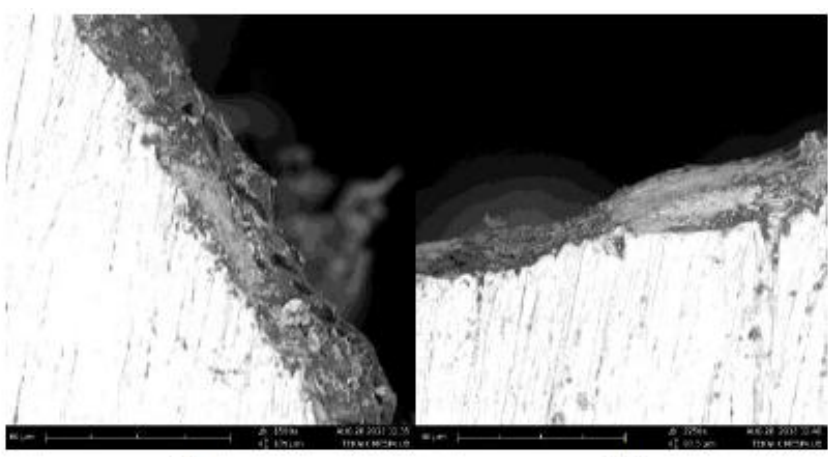

a)

Figures 4 and 5 show the cross section of the test specimen which shows the homogeneity of the layer formed nitride layer on the tool steels with chromium content of $1.07 \%$ is smooth with the test results an average surface roughness of $0.1 \mu \mathrm{m}$ while the carbon steel type AISI St 41 in which do not have the element chromium showed a greater surface roughness that is about $0.5 \mu \mathrm{m}$. This was evident in the results of the comparison test specimen microstructure is shown in Figure 6 . In addition to this, decreasing in the surface roughness by chrome content in low alloy steel will improved surface hardness. But, non-continuity of porosity on low alloy nitride compound layer which occurs by denitriding reaction must be considered.

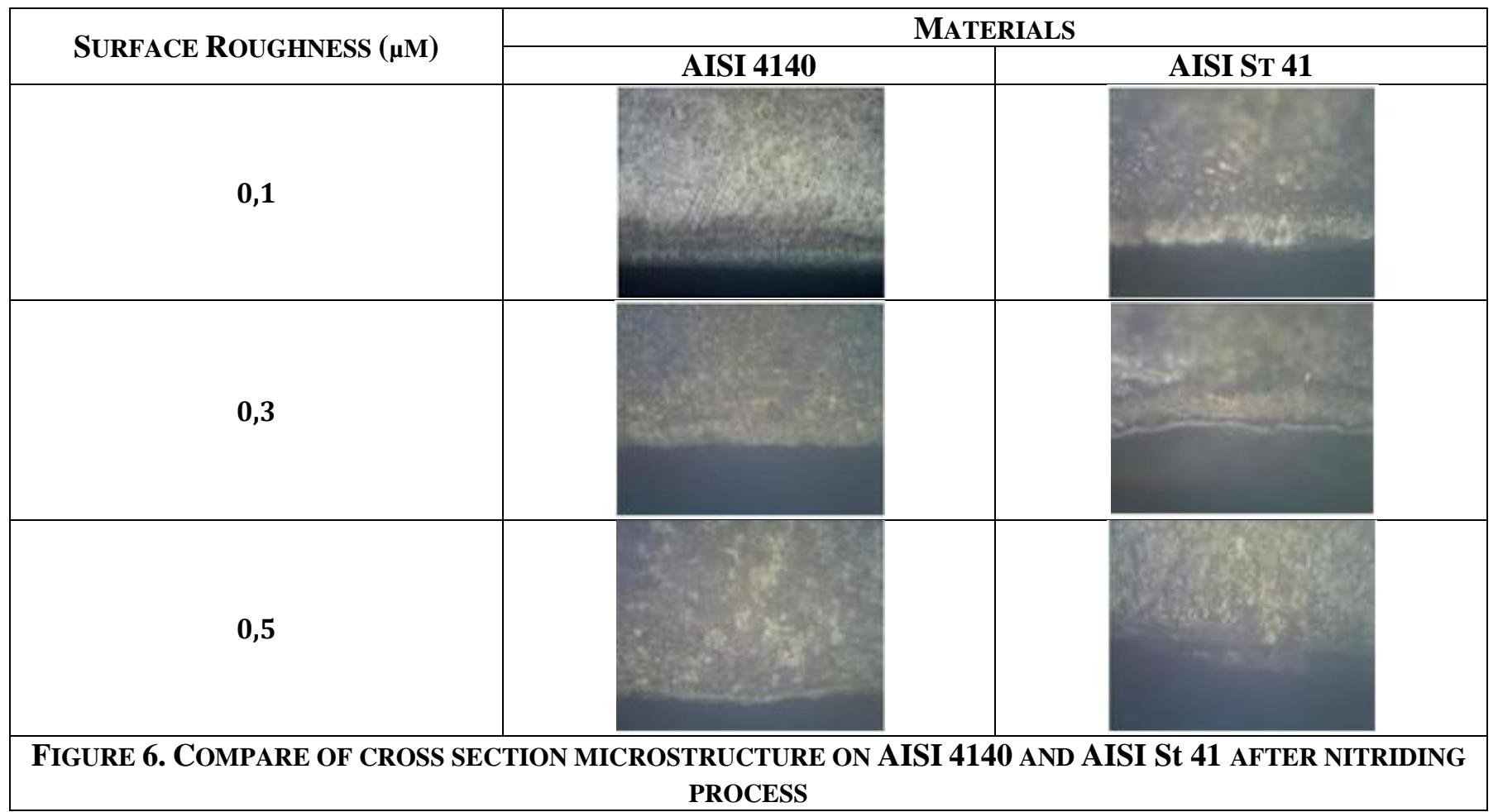

The presence of the element chromium nitriding process is very important in producing nitride layer morphology and characteristics. The formation of chromium and nitrogen reaction will give a better bond to the nitride layer with a lower 
level of porosit . Role elements besides chromium forms a bond with the $\mathrm{N}$ to form a nitride layer membeantu also reduce the release into the atmosphere of $\mathrm{N}$ atoms (reaction supersaturated) so that porosity can be minimized. This shows the ability of chromium is better to increase the wear resistance performance than Fe element in the process nitridisasi.

\section{CONCLUSION}

An investigation of the effects of surface roughness on carbon and low alloy steel after nitriding fluidised bed process has been done. We can conclude that the enhanced energetic nitrogen atoms would absorb at the steel surface and then diffuse faster into the matrix. Therefore, then nitriding depth in the diffusion layer is more significant form alloy steel (AISI 4140) with hardness between 715 - 872 HV compared with carbon steel (AISI St 41) with the surface hardness just only about 373 - $495 \mathrm{HV}$ after nitriding fluidized bed process. This result indicated that the diffusion rate of nitrogen atoms in alloys steel was much higher than that in carbon steel. A large amount of continues porosity in nitride compounds layers was when carbon steel was used in fluidized bed nitriding treatment and they caused surface roughness.

\section{ACKNOWLEDGEMENTS}

The author thanks the supports given by BPPS foundation from DIKTI and Materials Laboratory, Mechanical Engineering Department at ITN Malang.

\section{REFERENCES}

[1] R. W. Reynldson, Case Studies On The Use Of Fluidised Beds For The Heat Treatment of Metals, Heat Treatment in FluidisedBed Furnaces, ASM, 1993.

[2] E. Çelik, O. Çulha, B. Uyulgan, N.F. Ak Azem, I.Özdemir and A. Türk, "Assessment of microstructural and mechanical properties of HVOF sprayed WC-based cermet coatings for a roller cylinder," Surface \& Coatings Technology, SCT-11323, 2005.

[3] Gajendra Prasad Singh ${ }^{a}$, J. Alphonsa ${ }^{\text {b, , , P.K. Barhai }}{ }^{a}$, P.A. Rayjada ${ }^{b}$, P.M. Raole ${ }^{b}$, S. Mukherjee ${ }^{b}$ Effect of surface roughness on the properties of the layer formed on AISI 304 stainless steel after plasma nitriding, Surface and Coatings Technology, Volume 200, Issues 20-21, 22 May 2006, Pages 5807-5811.

[4] Khyoupin KhoO, Manabu Takeuchi, Jin Onuki, and Takao Komiyama, Improvement of the Surface Layer of Steel Using Microwave Plasma Nitriding, materials Transactions, Vol. 45, No. 3 (2004) pp. 942 to 946, 2004 The Japan Institute of Metals, Express Regular Article.

[5] Ş. Ekinci1, A. Akdemir and M.T.Demirci, Effect of Surface Roughness of Salt Bath Nitrided AISI 4140 to the Wear Rate, 6th International Advanced Technologies Symposium (IATS'11), 16-18 May 2011, Elazı̆̆ Turkey

[6] K. A. Widi, I.N.G. Wardana, W. Sujana, The effect of Chemical Compositions of Tool Steel On TheLevel of White Layers Homogeneity and The Surface Hardness, International Journal of Materials, Mechanics and Manufactureing, May 2013 , Vol I No 2.

[7] Insup Lee, Yong-Ho Park and Ikmin Park, The Characteristics of Surface Layers Produced On SKD 61 Steel By Plasma Radical Nitriding Compared With Conventional Plasma Ion Nitriding, Solid State Phenomena Vol. 118 (2006) pp 155-160, Trans Tech Publications, Switzerland, doi:10.4028/www.scientific.net/SSP.118.155.

[8] Widi K.A., Wardana I.N.G., Suprapto W., Irawan Y.S., (2016), The Role of Diffusion Media in Nitriding Process on Surface Layers Characteristics of AISI 4140 with and without Hard Chrome Coatings, Tribology in Industry, Vol. 38, No. 3 308-317.

[9] E. Haruman, Y. Sun, H. Malik, AG.E. Sutjipto, K. Widi, Low Temperatur Nitriding of Austenitc Stainless Steel, The 3 Asian Conference on Heat Treatment of Materials, Nov. 10-12 Gyeongiu, Korea, 2006

[10] J. Breckling, Ed., The Analysis of Directional Time Series: Applications to Wind Speed and Direction, ser. Lecture Notes in Statistics. Berlin, Germany: Springer, 1989, vol. 61.

[11] S. Zhang, C. Zhu, J. K. O. Sin, and P. K. T. Mok, "A novel ultrathin elevated channel low-temperature poly-Si TFT," IEEE Electron Device Lett., vol. 20, pp. 569-571, Nov. 1999. 